\title{
Abrupt termination of fluoxetine for depression led to an increase in dizziness and somnolence
}

\author{
Zajecka J, Fawcett J, Amsterdam J, et al. Safety of abrupt discontinuation of fluoxetine: a randomized, placebo-controlled study.J Clin \\ Psychopharmacol 1998 Jun;18:193-7.
}

\section{Question}

In patients who respond to fluoxetine treatment for depression, does abrupt termination of treatment lead to an increase in new or worsened adverse events?

\section{Design}

6 week randomised, double blind, placebo controlled trial.

\section{Setting}

Clinical centres in the US

\section{Patients}

395 patients (mean age $40 \mathrm{y}, 69 \%$ women) who showed an improvement in depressive symptoms (ie, scored $\leqslant 7$ on the 17 item Hamilton Rating Scale for Depression) after 12 weeks of fluoxetine, $20 \mathrm{mg} /$ day, for maintenance treatment of major depression, which was diagnosed according to DSM-III-R criteria.

\section{Assessment of risk factors}

Patients were allocated to continue fluoxetine, $20 \mathrm{mg} /$ day $(\mathrm{n}=299)$, or discontinue fluoxetine and receive a matching placebo $(\mathrm{n}=96)$.

\section{Main outcome measure}

Number of patients reporting new or worsened adverse events.

\section{Main results}

At 6 weeks, the number of patients reporting new or worsened adverse events did not differ between groups $(\mathrm{p}=0.19)$ (table). Patients who stopped fluoxetine treatment (placebo group) had more dizziness at week $4(\mathrm{p}=0.02)$ and more somnolence at week $2(\mathrm{p}=0.003)$ than those who continued treatment (table).
Differences were also seen for dysmenorrhoea, dizziness, and rhinitis at week 6 , which were all greater for placebo than fluoxetine, but these differences were based on data from $\leqslant 80 \%$ of patients. Withdrawals due to adverse events did not differ between groups. More patients withdrew from the placebo group than the fluoxetine group because of a lack of efficacy $(39 \%$ v $17 \%, \mathrm{p}<0.001)$.

\section{Conclusion}

In patients who responded to 12 weeks of fluoxetine treatment for major depression, an abrupt termination of treatment did not lead to an increase in overall adverse events at 6 weeks, although patients stopping treatment reported more dizziness at week 4 and somnolence at week 2 than did those continuing treatment.

Source of funding: none stated.

Placebo v continuation of fluoxetine after 12 weeks of fluoxetine for major depression*

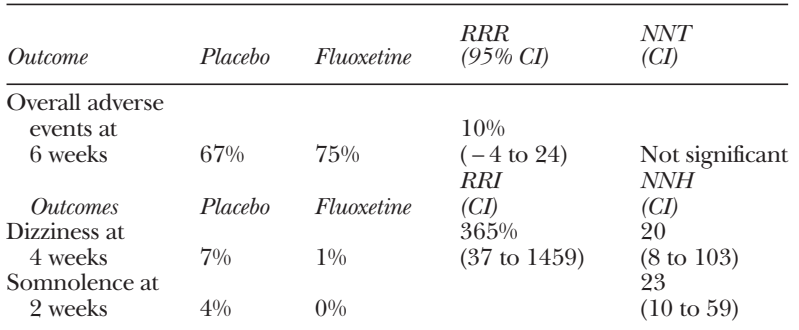

*Abbreviations defined in glossary; RRR, NNT, RRI, NNH, and CI calculated from data in article.

For correspondence: Dr I Zajecka, Department of Psychiatry, Rush-Presbyterian-St Luke's Medical Center, 1725 West Harrisom, Chicago, IL 60612, USA. Fax +13129422177.

\section{Commentary}

The history of the development of psychotropic drugs shows that the newest preparations are usually thought to be free of discontinuation syndromes until they have been used among sufficient numbers of patients, when symptoms after stopping treatment come increasingly to be recognised. Thus discontinuation syndromes have been identified for barbiturates, benzodiazepines, tricyclic antidepressants, and other psychotropic drugs in turn.

Reports of adverse symptoms after the discontinuation of selective serotonin reuptake inhibitors (SSRIs) and of patient reluctance to come off the drugs in some cases have been published recently. These reports have mostly concerned the discontinuation of paroxetine and sertraline, and have not reported on fluoxetine to the same extent. Furthermore, studies have been limited to 1-2 weeks follow up, and fluoxetine has a substantially longer half life which could delay the appearance of discontinuation symptoms until several weeks after stopping.

The strength of this study is that patients were followed up for 6 weeks after abrupt discontinuation of fluoxetine. The overall finding was that at 6 weeks the number of patients reporting new or worsened symptoms did not differ between the groups. It should be pointed out, however, that the sample size of the study had the power to detect only a relatively large difference between the 2 groups, of around $15 \%$, in the proportion of patients suffering symptoms. A clinically significant difference could therefore have been missed (a potential type II error).

Some differences were found, however; an increase in symptoms of dizziness, somnolence, rhinitis, and dysmenorrhoea occurred in the discontinuation group at varying intervals after cessation, although there was no cluster of symptoms suggestive of a specific discontinuation syndrome.

This study shows that non-specific symptoms such as dizziness and somnolence may emerge some 2-4 weeks after cessation of fluoxetine. Such symptoms should be short lived, and the temptation to investigate and treat them should be resisted initially. Studies with much larger samples are needed to exclude a specific SSRI discontinuation syndrome.

Tony Kendrick, MD, FRCGP University of Southampton Aldermoor Health Centre Southampton, UK 